\title{
Depression, Anxiety, and Perceived Social Support among Adults with Beta- Thalassemia Major: Cross-Sectional Study
}

\author{
Aghbabak Maheri', Roya Sadeghi' ${ }^{2}$ Davoud Shojaeizadeh ${ }^{2, *}$, Azar Tol${ }^{2}$, Mehdi Yaseri ${ }^{3}$, Alireza Rohban ${ }^{4}$ \\ ${ }^{1}$ Reproductive Health Research Center, Department of Public Health, School of Health, Urmia University of Medical Sciences, Urmia, Iran \\ ${ }^{2}$ Department of Health Education and Promotion, School of Public Health, Tehran University of Medical Sciences, Tehran, Iran \\ ${ }^{3}$ Department of Epidemiology and Biostatistics, School of Public Health, Tehran University of Medical Sciences, Tehran, Iran \\ ${ }^{4}$ Department of Rehabilitation Management, School of Rehabilitation Sciences, Iran University of Medical Sciences, Tehran, Iran
}

Background: Considering the high prevalence of depression and anxiety among thalassemia patients and the role of social support in preventing mental disorders, this study aimed to determine prevalence of depression, anxiety, and perceived social support (PSS) among adults with beta-thalassemia major.

Methods: This cross-sectional study was performed with 389 adults with beta-thalassemia major. Data were collected via a questionnaire consisting of three parts: demographic and medical information, the Persian version of the hospital anxiety and depression scale, and the Persian version of the Multidimensional Scale of Perceived Social Support. Data were analyzed using IBM SPSS ver. 23.0 (IBM Corp., Armonk, NY, USA) through analytical statistics (independent-samples t-test, one-way analysis of variance, Pearson correlation coefficient, and multilevel linear regression), and the results less than 0.05 were considered to be significant.

Results: The mean scores of depression, anxiety, and PSS of patients were 7.42 $\pm 3.17,7.47 \pm 4.35$, and $41.8 \pm 8.64$, respectively. Of 389 patients, $19.8 \%$ had depression and $23.7 \%$ had an anxiety disorder. Relationships of depression and anxiety with age, the level of education, job, and family income were statistically significant, as were those of PSS with age, thalassemia center, family income, job, and the level of education. PSS from family, friends, and significant others were the significant predictive factors of depression and anxiety among adult patients with betathalassemia major.

Conclusion: Considering the PSS as a factor influencing the reduction in depression and anxiety in thalassemia patients, social support from the social networks (spouse, family members, friends, and healthcare workers) should be integrated with interventions that are designed to improve the mental and physical health of thalassemia patients.

Keywords: Depression; Anxiety; Social Support; Beta-Thalassemia

Received: April 10, 2017, Revised: April 22, 2017, Accepted: May 8, 2017

*Corresponding Author: Davoud Shojaeizadeh https://orcid.org/0000-0003-2730-4795

Tel: +98-21-42933211, Fax: +98-21-88989129, E-mail: shojae5@yahoo.com 


\section{INTRODUCTION}

Thalassemia is one of the most common blood disorders and an inherited disease transmitted through parents to their children and it has no definitive cure. ${ }^{1)}$ Thalassemia is a disorder that is caused by a reduction in or failure of globin chain production and depending on what kind of globin chain is involved, thalassemia is categorized into $\alpha, \beta, \varepsilon \beta$, and so on. ${ }^{2)}$ Thalassemia has affected about $5 \%$ of the world population. ${ }^{3)}$

Beta-thalassemia is the kind of thalassemia caused by a reduction in or failure of beta-globin chain production. ${ }^{4)}$ In patients suffering from severe beta-thalassemia (beta-thalassemia major), deficiency of beta protein production in hemoglobin leads to life-threatening anemia and patient's life would depend on regular blood transfusion and constant medical care. ${ }^{4)}$ Every year, approximately 70,000 children are born with all kinds of thalassemia and more than $50 \%$ of them suffer from beta-thalassemia major. ${ }^{5)}$

In Iran, thalassemia is the most common genetic disease and Iran is located in the thalassemia belt. ${ }^{1)}$ About 3 million among the Iranian population are thalassemia gene carriers and about 26,000 people have thalassemia major; every year, 800 people are being added to this number ${ }^{6)}$ In Iran, the prevalence of beta-thalassemia is more than that of alpha-thalassemia. ${ }^{\text {7) }}$

A study of psychological well-being of thalassemia patients showed a very high prevalence of depression and anxiety among them. ${ }^{8)}$ One of the factors that increase the level of depression and anxiety is the lack of social support. In the other words, receiving social support can play a protective role against physical and mental health problems and decrease levels of depression and anxiety while facing life problems. ${ }^{9}$ Social support is defined as the financial and moral support from people close to the person who is in a stressful situation or in a hardship. ${ }^{9)}$ Based on the results of several studies, social support has a positive relationship with self-care in thalassemia and family are the most important while friends are the least important sources of social support for thalassemia patients, such that social support and family performance influence the mental condition of these patients. ${ }^{10)}$

Therefore, with regard to the high prevalence of depression and anxiety among thalassemia patients and the role of social supports in the control of depression and anxiety, this study was conducted to determine whether PSS is related to anxiety and depression in thalassemia patients and if so, which dimensions of PSS (family, friend, and significant others) more significantly predict depression and anxiety in the target group. This is a needs assessment study as a prerequisite for designing an intervention to reduce depression and anxiety by strengthening the PSS among thalassemia patients.

\section{METHODS}

In this cross-sectional investigation, we studied 389 adults with betathalassemia major who were referred to thalassemia centers affiliated with Tehran University of Medical Sciences (TUMS), Iran University of Medical Sciences (IUMS), and Iranian Blood Transfusion Organiza- tion (IBTO) between March 2015 and July 2016. The inclusion criteria were: being more than 18 years old, having a definitive diagnosis of beta-thalassemia major, giving informed and written consent for participation, and lacking other serious physical or mental health problem. The stratified random sampling was used. The total number of betathalassemia major patients over 18 years of age affiliated with TUMS, IUMS, and IBTO was 651 (according to statistics of Iranian Ministry of Health, 2015). ${ }^{11)}$ Among nine thalassemia centers at hospitals affiliated with TUMS, IUMS, and IBTO, the centers that had more than 50 adults with thalassemia major were identified as strata (Zafar Adult Thalassemia Clinic with 288 patients, Baharloo Hospital with 54 patients, Ali Asghar Children's Hospital with 70 patients, and Children's Medical Center Hospital with 103 patients were included in our study). Then, proportional to the number of patients in each stratum (center), the required samples were selected randomly within in each center. An ethical approval was obtained from TUMS (IR.TUMS.REC.1394.1153).

Data gathering instrument was a questionnaire consisting of three parts. The first part included medical and demographic information including age, sex, marital status, type of iron chelation therapy, blood transfusion interval, and levels of serum ferritin and hemoglobin before blood transfusion; and socio-economic status including the level of education (with four levels of illiterate, no high school diploma, high school diploma, and university degree), job (housewife, school student, university student, civil servant, self-employed, and unemployed), and family income (self-reported question was used to determine if the family income is sufficient or not, how the family manages monthly expenses with the present income? with difficulty or without difficulty). The second part included the Persian version of the Hospital Anxiety and Depression Scale. Zigmond and Snaith ${ }^{12)}$ had developed the questionnaire in 1983. This 15-items questionnaire is made to measure anxiety and depression. There are seven questions each related to anxiety and depression symptoms. The scoring is based on a 4-point scale (0, 1, 2, and 3). Totally, each part has 21 points. The total scores between zero and seven are considered as healthy, between eight and ten as borderline abnormality, and of eleven or more as abnormal. ${ }^{13)}$ This questionnaire can be applied to the general population as well as particular groups like elderly and hospitalized patients. Reliability and validity of the questionnaire have been evaluated by Montazeri et al. ${ }^{14)}$ in Iran, and the Cronbach's alpha coefficient for the reliability of depression and anxiety subscales is reported to be 0.78 and 0.86 , respectively. ${ }^{13,14)}$ The third part includes the Persian version of the Multidimensional Scale of Perceived Social Support. This questionnaire was made by Zimet et al. ${ }^{15)}$ in 1988 to measure PSS from family, friends, and significant others. It contains 12 questions based on a 5-point Likert scale ranging from "quite agree" to "quite disagree." After translation and cultural orientation of items to Iran, the questionnaire has been used in several studies, like the study of Mataji Amirrood et al. ${ }^{16)}$ High scores indicate receipt of more support from family, friends, and significant others in life. The questionnaire's total correlation in terms of Cronbach's alpha is reported to be 0.91 and for every dimension separately, it is reported to be between 0.90 and $0.95 .{ }^{17)}$ Iranian 
scholars have confirmed the reliability and validity of the Persian version of the questionnaire. ${ }^{16,18)}$

The obtained data were analyzed using IBM SPSS software ver. 23.0 (IBM Corp., Armonk, NY, USA) through descriptive statistics (mean, standard deviation, frequency, and percentage) and analytical statistics (independent-samples T-test, one-way analysis of variance, Pearson correlation coefficient, and multilevel linear regression). The results were considered to be significant at the conventional level of $\mathrm{P}<0.05$.

\section{RESULTS}

The total number of patients was 389 with a mean age of $30.23 \pm 8.3$ years. Most of them (56\%) were sampled from the Zafar Adult Thalas-

Table 1. Demographic/medical characteristics of the patients $(\mathrm{N}=389)$

\begin{tabular}{|c|c|}
\hline Variable & Number (\%) \\
\hline \multicolumn{2}{|l|}{ Thalassemia center } \\
\hline Children's Medical Center Hospital & $78(20.1)$ \\
\hline Ali Asghar Children Hospital & $53(13.6)$ \\
\hline Zafar Adult Thalassemia Clinic & $218(56.0)$ \\
\hline Baharloo Hospital & $40(10.3)$ \\
\hline \multicolumn{2}{|l|}{ Sex } \\
\hline Male & $179(46.0)$ \\
\hline Female & $210(54.0)$ \\
\hline \multicolumn{2}{|l|}{ Marital status } \\
\hline Single & $261(67.1)$ \\
\hline Married & $128(32.9)$ \\
\hline \multicolumn{2}{|l|}{ Level of education } \\
\hline Illiterate & $5(1.3)$ \\
\hline No high school diploma & $51(13.1)$ \\
\hline High school diploma & $171(44.0)$ \\
\hline University degree & $162(41.6)$ \\
\hline \multicolumn{2}{|l|}{ Job } \\
\hline Household & $60(15.4)$ \\
\hline School student & $11(2.8)$ \\
\hline University student & $44(11.3)$ \\
\hline Civil servant & $33(8.5)$ \\
\hline Self-employed & $167(42.9)$ \\
\hline Unemployed & $74(19.0)$ \\
\hline \multicolumn{2}{|l|}{ Family income sufficiency* } \\
\hline Yes & $237(60.9)$ \\
\hline No & $152(39.1)$ \\
\hline \multicolumn{2}{|c|}{ How often do you get a blood transfusion? } \\
\hline Every two weeks & $114(29.3)$ \\
\hline Every three weeks & $177(45.5)$ \\
\hline Each month & $71(18.3)$ \\
\hline Once in 2 to 3 months & $20(5.1)$ \\
\hline Sometimes/after long intervals & $7(1.8)$ \\
\hline \multicolumn{2}{|l|}{ Type of iron chelation therapy } \\
\hline Infusion & $182(46.8)$ \\
\hline Oral & $86(22.1)$ \\
\hline Combination & $107(27.5)$ \\
\hline None & $14(3.6)$ \\
\hline
\end{tabular}

*Definition of family income sufficiency is the individual's respondent is asked about how the family reaches the end of the month with its present income? With difficulty or without difficulty. semia Clinic. Almost $54 \%$ were women and $67.1 \%$ were single. The majority of patients had a university degree (44\%) and were self-employed (42.9\%). Most of them (60.9\%) reported that their family income meets their daily expenses. The blood transfusion interval was three weeks for most patients (45.5\%). The type of iron chelation therapy in most patients (46.8\%) was infusion. The mean levels of serum ferritin and hemoglobin before blood transfusion were 1,936.11 $\pm 1,604$ $\mathrm{ng} / \mathrm{mL}$ and $8.9 \pm 1.03 \mathrm{~g} / \mathrm{dL}$, respectively (Tables 1,2 ).

The mean scores of depression and anxiety among the patients with thalassemia major were $7.42 \pm 3.17$ and $7.47 \pm 4.35$, respectively. The mean scores of total PSS and on the subscales of family, friends, and significant others were $41.8 \pm 8.64,14.01 \pm 4.11,15.6 \pm 3.03$, and $12.18 \pm 3.76$, respectively. Based on the results, 77 patients $(19.8 \%)$ had depression (abnormal) and 99 (25.4\%) were prone to depression (borderline abnormality). Further, 92 patients (23.7\%) had anxiety (abnormal) and $86(22.1 \%)$ were prone to anxiety (borderline abnormality) (Table 2).

The mean scores and standard deviation of depression, anxiety, and total PSS and its subscales (family, friends, and significant others) are presented in Table 3 along with demographic and medical characteristics. There was a statistically significant relationship between the thalassemia center and the mean scores of PSS, as determined by the results of a post hoc test (least significant difference), and so the mean scores of PSS in adult patients of Children's Medical Center were significantly higher than that of patients of the Zafar Adult Thalassemia Clinic and Ali Asghar Children's Hospital. The mean scores of PSS did not differ significantly within the other centers (the results of post hoc test and comparing each center with an another center).

The findings of this study showed that the level of education was significantly associated with the mean scores of depression, anxiety, and PSS of patients, as determined by the results of a post hoc test, and so the mean scores of depression of patients with a university degree was significantly lower than that of those with and without high school diploma and illiterate patients. Additionally, the mean scores of depression of patients with high school diploma were significantly lower than that of those without high school diploma and illiterate patients. Furthermore, the mean scores of anxiety of patients with a university degree were significantly lower than that of those with and without

Table 2. Mean and standard deviation of demographic/medical characteristics and scores of depression, anxiety, and perceived social support

\begin{tabular}{lc}
\hline \multicolumn{1}{c}{ Variable } & Mean \pm standard deviation \\
\hline Age $(\mathrm{y})$ & $30.23 \pm 8.3$ \\
Serum ferritin level based on the last test result $(\mathrm{ng} / \mathrm{mL})$ & $1,936.11 \pm 1,604$ \\
Hemoglobin level based on the last test result $(\mathrm{g} / \mathrm{dL})$ & $8.9 \pm 1.03$ \\
Depression & $7.42 \pm 3.17$ \\
Anxiety & $7.47 \pm 4.35$ \\
Perceived social support & \\
Family & $15.6 \pm 3.03$ \\
Friends & $12.18 \pm 3.76$ \\
Significant others & $14.01 \pm 4.11$ \\
Total & $41.8 \pm 8.64$ \\
\hline
\end{tabular}


Table 3. The mean and standard deviation of scores of depression, anxiety, and perceived social support according to demographic/medical characteristics of the patients

\begin{tabular}{|c|c|c|c|c|c|c|}
\hline \multirow{2}{*}{ Demographic/medical characteristic } & \multicolumn{2}{|c|}{ Depression } & \multicolumn{2}{|c|}{ Anxiety } & \multicolumn{2}{|c|}{ Perceived social support } \\
\hline & Mean \pm SD & P-value & Mean \pm SD & P-value & Mean \pm SD & P-value \\
\hline Thalassemia center & & $0.052^{\dagger}$ & & $0.136^{\dagger}$ & & $0.005^{\star *, \dagger}$ \\
\hline Children's Medical Center Hospital & $6.67 \pm 3.19$ & & $7.22 \pm 4.52$ & & $44.74^{\mathrm{a}, \mathrm{b}} \pm 7.67$ & \\
\hline Ali Asghar Children Hospital & $8.15 \pm 3.77$ & & $8.77 \pm 5.63$ & & $40.72^{\mathrm{a}} \pm 10.98$ & \\
\hline Zafar Adult Thalassemia Clinic & $7.46 \pm 3.06$ & & $7.25 \pm 3.97$ & & $40.88^{b} \pm 8.39$ & \\
\hline Baharloo Hospital & $7.78 \pm 2.67$ & & $7.48 \pm 3.93$ & & $42.62 \pm 7.02$ & \\
\hline Sex & & $0.344^{\ddagger}$ & & $0.217^{\ddagger}$ & & $0.140^{\ddagger}$ \\
\hline Male & $7.59 \pm 2.94$ & & $7.18 \pm 3.90$ & & $41.12 \pm 7.36$ & \\
\hline Female & $7.29 \pm 3.36$ & & $7.72 \pm 4.70$ & & $42.40 \pm 9.57$ & \\
\hline Marital status & & $0.124^{\ddagger}$ & & $0.727^{\ddagger}$ & & $0.367^{\ddagger}$ \\
\hline Single & $7.25 \pm 3.19$ & & $7.42 \pm 4.40$ & & $41.53 \pm 9.09$ & \\
\hline Married & $7.78 \pm 3.12$ & & $7.59 \pm 4.28$ & & $42.38 \pm 7.65$ & \\
\hline Level of education & & $0.001^{* *, \dagger}$ & & $0.001^{* *, \dagger}$ & & $0.001^{* *, \dagger}$ \\
\hline Illiterate & $11.60^{\mathrm{a}, \mathrm{b}} \pm 2.70$ & & $13.60^{\mathrm{a}, \mathrm{b}, \mathrm{c}} \pm 4.27$ & & $29.00^{a, b, c} \pm 7.93$ & \\
\hline No high school diploma & $8.82^{\mathrm{c,d}} \pm 2.74$ & & $7.86^{\mathrm{a}, \mathrm{d}} \pm 3.74$ & & $39.63^{\mathrm{a}, \mathrm{d}} \pm 9.35$ & \\
\hline High school diploma & $7.86^{\mathrm{a}, \mathrm{c}, \mathrm{e}} \pm 2.97$ & & $8.09^{b, e} \pm 4.33$ & & $40.58^{\mathrm{b}, \mathrm{e}} \pm 8.49$ & \\
\hline University degree & $6.40^{\mathrm{b}, \mathrm{de}, \mathrm{e}} \pm 3.17$ & & $6.51^{\mathrm{c}, \mathrm{d}, \mathrm{e} e} \pm 4.30$ & & $44.19^{\mathrm{c}, \mathrm{d}, \mathrm{e}} \pm 7.81$ & \\
\hline Job & & $0.003^{* *, \dagger}$ & & $0.005^{\star \star, \dagger}$ & & $0.019^{*, \dagger}$ \\
\hline Household & $7.98^{\mathrm{a}, \mathrm{b}} \pm 3.11$ & & $9.12^{\mathrm{a}, \mathrm{b}, \mathrm{c}} \pm 4.72$ & & $41.28 \pm 9.55$ & \\
\hline School student & $7.36 \pm 2.90$ & & $6.00^{\mathrm{a}} \pm 2.93$ & & $45.27^{\mathrm{a}} \pm 10.24$ & \\
\hline University student & $6.18^{\mathrm{a}, \mathrm{c}, \mathrm{d}} \pm 3.58$ & & $6.82^{\mathrm{b}} \pm 5.20$ & & $43.98^{\mathrm{b}, \mathrm{c}} \pm 8.60$ & \\
\hline Civil servant & $8.27^{\mathrm{c}, \mathrm{e}} \pm 3.62$ & & $7.79 \pm 3.59$ & & $39.94^{b} \pm 6.38$ & \\
\hline Self-employed & $7.04^{\mathrm{b}, e, f} \pm 2.86$ & & $6.80^{\mathrm{c}, \mathrm{d}} \pm 4.07$ & & $42.62^{\mathrm{d}} \pm 7.34$ & \\
\hline Unemployed & $8.22^{\mathrm{d}, \mathrm{f}} \pm 3.19$ & & $8.15^{\mathrm{d}} \pm 4.23$ & & $39.43^{\mathrm{a}, \mathrm{c}, \mathrm{d}} \pm 10.54$ & \\
\hline Family income sufficiency & & $0.001^{* *, \neq}$ & & $0.001^{* *, \neq}$ & & $0.001^{* * \neq}$ \\
\hline Yes & $6.84 \pm 3.11$ & & $6.58 \pm 4.19$ & & $43.62 \pm 7.44$ & \\
\hline No & $8.35 \pm 3.06$ & & $8.88 \pm 4.25$ & & $38.98 \pm 9.602$ & \\
\hline How often do you get a blood transfusion? & & $0.497^{\dagger}$ & & $0.436^{\dagger}$ & & $0.310^{\dagger}$ \\
\hline Every two weeks & $7.75 \pm 3.211$ & & $7.82 \pm 3.99$ & & $40.51 \pm 8.42$ & \\
\hline Every three weeks & $7.14 \pm 3.14$ & & $7.06 \pm 4.30$ & & $42.44 \pm 9.25$ & \\
\hline Every month & $7.59 \pm 3.40$ & & $7.58 \pm 4.88$ & & $42.52 \pm 7.94$ & \\
\hline Once in 2 to 3 months & $7.75 \pm 2.55$ & & $8.60 \pm 4.55$ & & $40.50 \pm 6.32$ & \\
\hline Sometimes/after long intervals & $6.71 \pm 2.69$ & & $8.00 \pm 5.26$ & & $43.71 \pm 7.65$ & \\
\hline Type of iron chelation & & $0.057^{\dagger}$ & & $0.672^{\dagger}$ & & $0.196^{\dagger}$ \\
\hline Infusion & $7.63 \pm 3.18$ & & $7.23 \pm 4.08$ & & $41.39 \pm 8.04$ & \\
\hline Oral & $7.13 \pm 3.19$ & & $7.64 \pm 4.95$ & & $42.91 \pm 9.18$ & \\
\hline Combination & $7.08 \pm 3.09$ & & $7.64 \pm 4.17$ & & $42.14 \pm 8.34$ & \\
\hline None & $9.29 \pm 3.14$ & & $8.43 \pm 5.43$ & & $38.00 \pm 13.46$ & \\
\hline
\end{tabular}

Same alphabet letters demonstrate the statistically significant difference between two groups based on Bonferroni correction method.

${ }^{*} \mathrm{P}<0.05$. ${ }^{* *} \mathrm{P}<0.01$. ${ }^{\dagger}$ By one-way analysis of variance. ${ }^{*}$ By independent-samples t-test.

high school diploma and illiterate patients, and the mean scores of anxiety of illiterate patients were significantly higher than that of those with and without high school diploma. Moreover, the mean scores of PSS of patients with a university degree were significantly higher than that of those with and without high school diploma and illiterate patients; for illiterate patients, the mean scores of PSS were significantly lower than that of patients with and without high school diploma.

The statistical analysis revealed a significant relationship between occupation and the mean scores of depression, anxiety, and PSS of patients, as determined by the results of a post hoc test; thus, the mean scores of depression were significantly higher in housewife than university students and self-employed individuals, and were significantly lower in university students than civil servants and the unemployed, and were significantly higher in civil servants than self-employees, and were significantly lower in the self-employed than the unemployed. In addition, the mean scores of anxiety were significantly higher in households than university students, high school students, and the self-employed; they were significantly lower in the self-employed than the unemployed. Moreover, the mean scores of PSS were significantly lower in the unemployed than university students, school students, and the self-employed; they were significantly higher in university students than civil servants.

The research findings also revealed that there was a statistically significant relationship between family income and the mean scores of depression, anxiety, and PSS in patients; thus, the mean scores of depression and anxiety was significantly lower and the mean scores of 
Table 4. The correlation matrix of study variables

\begin{tabular}{|c|c|c|c|c|c|c|c|}
\hline Variable & 1 & 2 & 3 & 4 & 5 & 6 & 7 \\
\hline Depression & 1 & & & & & & \\
\hline Anxiety & $0.573^{* *}$ & 1 & & & & & \\
\hline Perceived social support from family & $-0.439^{* *}$ & $-0.384^{\star \star}$ & 1 & & & & \\
\hline Perceived social support from friends & $-0.448^{\star \star}$ & $-0.313^{\star *}$ & $0.317^{\star *}$ & 1 & & & \\
\hline Perceived social support from significant others & $-0.417^{\star *}$ & $-0.361^{\star *}$ & $0.502^{\star \star}$ & $0.471^{\star \star}$ & 1 & & \\
\hline Perceived social support (total) & $-0.548^{\star \star}$ & $-0.443^{\star *}$ & $0.728^{* *}$ & $0.771^{* *}$ & $0.858^{* *}$ & 1 & \\
\hline Age & $0.229^{\star \star}$ & $0.127^{*}$ & $-0.168^{\star *}$ & $-0.263^{\star *}$ & $-0.132^{* *}$ & $-0.236^{\star *}$ & 1 \\
\hline
\end{tabular}

${ }^{*} \mathrm{P}<0.05 .{ }^{* *} \mathrm{P}<0.01$.

PSS was significantly higher in those who reported that their family income meets their daily expenses than those who reported otherwise. The mean scores of depression were lower in those who used chelation therapy than the other patients, but this was not found to be highly significant ( $\mathrm{P}=0.057)$ (Table 3 ).

Based on the results, PSS and all its subscales were significantly negatively correlated with anxiety and depression each; and so while the mean scores of PSS increased, the mean scores of depression and anxiety decreased. Moreover, there was a significant positive correlation between the age of patients and mean scores of depression and anxiety as well as significant negative correlation of PSS and its subscales with the age of patients; thus, while the age of patients increased, the mean scores of depression and anxiety increased, whereas the mean scores of PSS decreased (Table 4).

Finally, based on the results of multilevel linear regression, the PSS from family $(\beta=-0.242, P<0.001)$, friends $(\beta=-0.202, P<0.001)$, and significant others $(\beta=-0.092, \mathrm{P}<0.046)$ were the significant predictive factors of depression amongst adults with beta-thalassemia major, such that the PSS from family, friends, and significant others each independently had a significant negative correlation with depression. The strongest predictive factor of depression was the PSS from family $(\beta=$ $-0.242)$. Besides, the PSS from family $(\beta=-0.304, P<0.001)$, friends $(\beta=$ $-0.135, \mathrm{P}<0.036)$, and significant others $(\beta=-0.177, \mathrm{P}<0.009)$ were the significant predictive factors of anxiety amongst adults with beta-thalassemia major, such that the PSS from family, friends, and significant others, each independently had a significant negative correlation with anxiety. The strongest predictive factor of anxiety was the PSS from family $(\beta=-0.304)$ (Table 5).

\section{DISCUSSION}

According to the results of this study, the percentage of thalassemia patients who were prone to depression and anxiety is $19.8 \%$ and $23.7 \%$, respectively. The high level of depression and anxiety among thalassemia patients is not an unexpected issue and it has been confirmed and reported by the several studies, ${ }^{8,19,20)}$ which could be due to chronic nature of thalassemia, medical costs, and premature death expectancy ${ }^{9)}$ The results of the mentioned studies indicate the necessity of implementation of screening programs to diagnose and begin early treatment of depression and anxiety of thalassemia patients as well as
Table 5. Predictive factors of depression/anxiety among the patients as determined using multilevel linear regression analysis

\begin{tabular}{lcccr}
\hline $\begin{array}{c}\text { Perceived social } \\
\text { support }\end{array}$ & $\begin{array}{c}\text { Regression } \\
\text { coefficient }\end{array}$ & $\begin{array}{c}\text { Standard } \\
\text { error }\end{array}$ & $\begin{array}{c}95 \% \text { confidence } \\
\text { interval }\end{array}$ & P-value \\
\hline $\begin{array}{l}\text { Depression* } \\
\text { Family }\end{array}$ & -0.242 & 0.052 & -0.345 to -0.139 & $<0.001$ \\
$\quad$ Friends & -0.202 & 0.044 & -0.288 to -0.115 & $<0.001$ \\
$\quad$ Significant others & -0.092 & 0.046 & -0.183 to -0.001 & 0.046 \\
Anxiety & & & & \\
$\quad$ Family & -0.304 & 0.076 & -0.454 to -0.153 & $<0.001$ \\
$\quad$ Friends & -0.135 & 0.064 & -0.262 to -0.009 & 0.036 \\
$\quad$ Significant others & -0.177 & 0.067 & -0.309 to -0.044 & 0.009 \\
\hline
\end{tabular}

*Adjusted for age, sex, marital status, level of education, job, family income sufficiency, blood transfusion interval, type of iron chelation therapy, levels of serum ferritin, and hemoglobin.

using the knowledge and expertise of psychiatrists and clinical psychologists in thalassemia centers.

In our study, among PSS subscales, the highest score was for family and the lowest was for friends; therefore, it can be concluded that family and friends are respectively the most and the least important sources of social support for adults suffering from beta-thalassemia major. Relatively comparable results were obtained in the study of Yang et al. ${ }^{10)}$ and Hooshmandi et al. ${ }^{19)}$ indicating that family and friends are respectively the most and the least important sources of social support for thalassemia patients. Considering the fact that the family is the most important source of social support in thalassemia patients, designing and implementing health education and promotion interventions to inform thalassemia patients' families about the role of social support received through families, in improving physical and mental health of thalassemia patients seems necessary.

PSS from family, friends, and significant others were the significant predictive factors of depression and anxiety among adults with betathalassemia major; thus, we observed a reduction in the level of depression and anxiety in thalassemia patients as the PSS from family, friends, and significant others increased and vice versa. The relationship of PSS with depression and anxiety has been confirmed in the previous literature. ${ }^{21-23)}$ Findings similar to ours were observed in the study of Hooshmandi et al., ${ }^{19)}$ which was conducted with patients with thalassemia major in Bushehr, Iran, and demonstrated the significant negative correlation of the total PSS and subscales of family and signif- 
icant others with the level of depression in thalassemia patients. Given that receiving social support from social networks like spouse, family members, friends, and healthcare workers through financial, emotional, and informational aids, can improve the patient's physical and mental health, ${ }^{9)}$ designing and evaluating health education and promotion interventions to strengthen the social support system for thalassemia patients is essential. To achieve this goal, monitoring the level of depression, anxiety, and PSS of thalassemia patients should be integrated into the medical protocol and routine care programs. Access to the social support system, especially family support for thalassemia patients dealing with depression and anxiety should be facilitated and strengthened.

According to the results of this study, a higher level of education was associated with a lower level of depression and anxiety among thalassemia patients. In line with our findings, in the study of Poormansouri et al., ${ }^{24)}$ the level of education appeared to have a significant relationship with depression and anxiety, as, with an increase in education, the level of depression and anxiety decreased. Similar results were also obtained by the study of Khamoushi et al. ${ }^{25)}$ People with higher education have always tended to have higher socioeconomic status and income as well as higher life satisfaction and quality of life. The high level of education also helps patients cope with the disease and to continue treatment, and so the level of depression and anxiety among thalassemia patients with higher education will decrease. ${ }^{24,25)}$ The level of depression and anxiety of employed patients in our study was lower than that of unemployed patients, confirming the earlier evidence in the study of Khamoushi et al. ${ }^{25)}$ Due to higher income in among employed, it is expected that they have better quality of life and life satisfaction, and consequently, the level of depression and anxiety among them will be lower. ${ }^{24,25}$ The mean level of anxiety and depression was significantly lower among patients who reported that their family income meets their daily expenses compared to those who reported that their family was in financial hardship, which is in line with some studies. $^{24,25)}$

Based on our results, a statistically significant relationship was found of PSS with the level of education, occupation, and family income; thus, higher education among thalassemia patients led to higher scores of PSS among them. Additionally, the level of PSS was higher for employed than unemployed patients, and also for those with sufficient income than people with insufficient income, which was consistent with previous literature. ${ }^{26,27)}$ People with higher education and employed people usually have more interpersonal communication and have a chance to be in different societies and organizations, and subsequently, have more opportunities to find friends who would support them. A high income can also be a great source of support for people, $^{26,27)}$ and higher education leads to more access to information and financial resources, and as a result, results in strong social support. ${ }^{28)}$

The present study noted that as the age of patients increased, the mean scores of depression and anxiety increased, and the mean scores of PSS decreased. These findings are in agreement with the studies conducted by Khamoushi et al. ${ }^{25)}$ and Soltani et al. ${ }^{27)}$ It is obvious that while age increases, the financial independence and experience and knowledge of people increases, which means that demand for support and counseling decreases. ${ }^{29)}$

According to our results, there was no statistically significant relationship of the type of iron chelation therapy and blood transfusion interval with the mean scores of depression, anxiety, and PSS in patients, which is consistent with the results of Mednick et al. ${ }^{8)}$ Additionally, Mednick et al. ${ }^{8)}$ did not find a statistically significant relationship of the type of iron chelation therapy and frequency of blood transfusion with the mean scores of depression and anxiety in thalassemia patients. However, according to the results of other studies, medical characteristics (such as serum ferritin level, type of iron chelation therapy, and so on) have been introduced as factors affecting psychological disorders in patients with beta thalassemia major. ${ }^{30}$ Further studies should be done in this area to confirm this result.

This study highlights the high level of depression and anxiety among thalassemia patients; therefore, an effort should be made to design and evaluate a variety of interventions, including those for health education and promotion, in order to decrease the level of depression and anxiety among these patients. Further, due to the effectiveness of PSS from family, friends, and significant others on depression and anxiety reduction in thalassemia patients, social support received from social networks like the spouse, family members, friends, and healthcare workers should be integrated into the interventions that are conducted to improve the physical and mental health of thalassemia patients. Ultimately, knowledge, skill, and expertise of health educators, psychiatrists, and psychologists in thalassemia centers should be directed towards achieving the goals mentioned above.

There was a limitation in our study. To measure anxiety and depression in patients, we used the Hospital Anxiety and Depression Scale, which is a self-assessment scale only valid for screening purposes; therefore, using clinical examination for definitive diagnosis of anxiety and depression is recommended for similar future studies.

\section{CONFLICT OF INTEREST}

No potential conflict of interest relevant to this article was reported.

\section{REFERENCES}

1. Renani HA, Dashtbozorgi B, Papi M, Navah A, Latifi SM. The relationship between social capital and self-concept in adolescents with thalassemia major. Jundishapur J Chronic Dis Care 2016;5:e31306.

2. Langlois S, Ford JC, Chitayat D; CCMG Prenatal Diagnosis Committee; SOGC Genetics Committee. Carrier screening for thalassemia and hemoglobinopathies in Canada. J Obstet Gynaecol Can 2008;30:950-9.

3. Rahim F, Abromand M. Spectrum of $§$-thalassemia mutations in various ethnic regions of Iran. Pak J Med Sci 2008;24:410-5.

4. Rivella S. $\beta$-thalassemias: paradigmatic diseases for scientific discoveries and development of innovative therapies. Haematologica 2015;100:418-30.

5. Mettananda S, Gibbons RJ, Higgs DR. $\alpha$-Globin as a molecular target 
in the treatment of $\beta$-thalassemia. Blood 2015;125:3694-701.

6. Maheri A, Sadeghi R, Shojaeizadeh D, Tol A, Yaseri M, Ebrahimi M. Associations between a health-promoting lifestyle and quality of life among adults with beta-thalassemia major. Epidemiol Health 2016;38:e2016050.

7. Khodaei GH, Farbod N, Zarif B, Nateghi S, Saeidi M. Frequency of thalassemia in Iran and Khorasan Razavi. Int J Pediatr 2013;1:45-50.

8. Mednick L, Yu S, Trachtenberg F, Xu Y, Kleinert DA, Giardina PJ, et al. Symptoms of depression and anxiety in patients with thalassemia: prevalence and correlates in the thalassemia longitudinal cohort. Am J Hematol 2010;85:802-5.

9. Yildiz E, Asti T. Determine the relationship between perceived social support and depression level of patients with diabetic foot. J Diabetes Metab Disord 2015;14:59.

10. Yang HC, Chen YC, Mao HC, Lin KH. Illness knowledge, social support and self care behavior in adolescents with beta-thalassemia major. Hu Li Yan Jiu 2001;9:114-24.

11. Iranian Ministry of Health and Medical Education. Statistics of Iranian Ministry of Health [Internet]. Tehran: Iranian Ministry of Health and Medical Education; 2015 [cited 2017 Dec 9]. Available from: http:// www.behdasht.govir.

12. Zigmond AS, Snaith RP. The hospital anxiety and depression scale. Acta Psychiatr Scand 1983;67:361-70.

13. Ebadi A, Moradian ST, Feyzi F, Asiabi M. Comparison of the hospital anxiety and depression among patients with coronary artery disease based on proposed treatment. Iran J Crit Care Nurs 2011;4:97-102.

14. Montazeri A, Vahdaninia M, Ebrahimi M, Jarvandi S. The Hospital Anxiety and Depression Scale (HADS): translation and validation study of the Iranian version. Health Qual Life Outcomes 2003;1:14.

15. Zimet GD, Dahlem NW, Zimet SG, Farley GK. The multidimensional scale of perceived social support. J Pers Assess 1988;52:30-41.

16. Maryam Mataji Amirrood M, Taghdisi MH, Shidfar F, Mahmood Reza G. The relationship between perceived social support and obesity preventive eating behavior in women of Urmia City in 2012. Razi J Med Sci 2014;21:1-11.

17. Canty-Mitchell J, Zimet GD. Psychometric properties of the Multidimensional Scale of Perceived Social Support in urban adolescents. Am J Community Psychol 2000;28:391-400.

18. Mohamadian H, Eftekhar H, Rahimi A, Mohamad HT, Shojaiezade D, Montazeri A. Predicting health-related quality of life by using a health promotion model among Iranian adolescent girls: a structural equa- tion modeling approach. Nurs Health Sci 2011;13:141-8.

19. Hooshmandi R, Akabarian S, Bahreini M, Mirzaei K. The relationship between social support and depression in patients with thalassemia major in Bushehr, Iran. NJV 2015;2:1-14.

20. Mikelli A, Tsiantis J. Brief report: depressive symptoms and quality of life in adolescents with b-thalassaemia. J Adolesc 2004;27:213-6.

21. Pinar G, Okdem S, Buyukgonenc L, Ayhan A. The relationship between social support and the level of anxiety, depression, and quality of life of Turkish women with gynecologic cancer. Cancer Nurs 2012;35:229-35.

22. Wu SF, Young LS, Yeh FC, Jian YM, Cheng KC, Lee MC. Correlations among social support, depression, and anxiety in patients with type-2 diabetes. J Nurs Res 2013;21:129-38.

23. Ghorbani Saeedian R, Nagyova I, Krokavcova M, Skorvanek M, Rosenberger J, Gdovinova Z, et al. The role of social support in anxiety and depression among Parkinson's disease patients. Disabil Rehabil 2014;36:2044-9.

24. Poormansouri S, Ahmadi M, Shariati AA, Keikhaei B. Quality of life, depression, anxiety and stress in over-18-year-old patients with betathalassemia major. Sci J Iran Blood Transfus Organ 2016;13:72-82.

25. Khamoushi F, Ahmadi SM, Karami-Matin B, Ahmadi-Jouybari T, Mirzaei-Alavijeh M, Ataee M, et al. Prevalence and socio-demographic characteristics related to stress, anxiety, and depression among patients with major thalassemia in the Kermanshah County. J Biol Today's World 2015;4:79-84.

26. Harley K, Eskenazi B. Time in the United States, social support and health behaviors during pregnancy among women of Mexican descent. Soc Sci Med 2006;62:3048-61.

27. Soltani T, Mazloomy Mahmoudabad SS, Morowati Sharifabad MA, Fallahzadeh H, Jafari A. Social support and its relation with daily activities among elderly people of Yazd. J Commun Health Res 2015; 3:2707.

28. Arafa MA, Nazel MW, Ibrahim NK, Attia A. Predictors of psychological well-being of nurses in Alexandria, Egypt. Int J Nurs Pract 2003;9:31320.

29. Akouchekian SH, Roohafza HR, Mohammad Sharifi H. Relation between social support and coping with stress in nurses in psychiatric ward. J Guilan Univ Med Sci 2009;18:41-6.

30. Naderi M, Hormozi MR, Ashrafi M, Emamdadi A. Evaluation of mental health and related factors among patients with beta-thalassemia major in South East of Iran. Iran J Psychiatry 2012;7:47-51. 